\title{
Qualidade da água de córrego em função do lançamento de efluente de abate de bovino
}

\author{
Erlon A. Ribeiro' ${ }^{1}$ Delvio Sandri ${ }^{2}$ \& Josianny A. Boêno ${ }^{3}$
}

\begin{abstract}
RESUMO
Objetivou-se, com este trabalho, avaliar a influência do lançamento de efluente de um frigorífico de abate de bovinos sobre a qualidade da água do córrego Jurubatuba, Anápolis, GO. Analisaram-se: o efluente tratado antes do lançamento no córrego e a água do córrego $50 \mathrm{~m}$ à montante e 50 e $500 \mathrm{~m}$ à jusante do ponto de lançamento. Foram realizadas oito coletas no período seco (08/07 a 24/09/09) e oito no chuvoso (01/10 a 03/12/09) quantificando o $\mathrm{pH}$, turbidez, oxigênio dissolvido, saturação de oxigênio, carbono orgânico total, cloro, alumínio, amônia, cobre, manganês, ferro total, fósforo total, sulfeto, sódio, demanda biológica de oxigênio, demanda química de oxigênio, nitrogênio total, condutividade elétrica, nitrato e nitrito. Os valores de $\mathrm{pH}, \mathrm{NH}_{3}{ }^{-}, \mathrm{Zn}^{+}$, sulfeto, $\mathrm{NO}_{3}{ }^{-}$, e cloreto nos dois períodos e em todos os pontos analisados no córrego, atenderam aos critérios para água de classe 2; $\mathrm{o} \mathrm{Na}^{+}, \mathrm{NH}_{3}$; carbono orgânico total, $\mathrm{P}$ total, $\mathrm{CE}$ e $\mathrm{NO}_{3}{ }^{-}$aumentaram nos pontos após o lançamento do efluente. A turbidez, $\mathrm{Al}$ e o $\mathrm{Mg}$ no efluente tratado foram, nos períodos seco e chuvoso, maiores ao permitido para corpos hídricos de classe 2; o Fe total no efluente apresentou risco médio para uso na irrigação.
\end{abstract}

Palavras-chave: água residuária, tratamento de resíduos, DBO, recursos hídricos

\section{Water quality of stream due to release of effluent from cattle slaughter}

\begin{abstract}
The objective of this study was to evaluate the influence of release of effluent from a cattle slaughter house on water quality of Jurubatuba stream, in Anápolis - Goiás. The treated effluent before release into the stream, the stream water at $50 \mathrm{~m}$ upstream, and 50 and $500 \mathrm{~m}$ downstream from the launch place were analysed. Eight samples were taken during the dry season (08/07 to 24/09/2009) and eight in the rainy season (01/10 to 03/12/2009), quantifying $\mathrm{pH}$, turbidity, dissolved oxygen, oxygen saturation, total organic carbon, chlorine, aluminum, ammonia, copper, manganese, total iron, total phosphorus, sulfate, sodium, biological oxygen demand, chemical oxygen demand, total nitrogen, electrical conductivity, nitrate and nitrite. The values of $\mathrm{pH}, \mathrm{NH}_{3}^{-}, \mathrm{Zn}^{++}$, sulfide, $\mathrm{NO}_{3}$, chloride during the two periods at all analyzed points matched the criteria of water of class $2 . \mathrm{Na}^{+}, \mathrm{NH}_{3}$, total organic carbon, total $\mathrm{P}, \mathrm{CE}$ and $\mathrm{NO}_{3}$ increase at some points after the release of the effluent. Turbidity, $\mathrm{Al}$ and $\mathrm{Mg}$ in the treated effluent during dry and rainy season were higher than allowed for class 2 water bodies; total Fe in the effluent had medium risk for use in irrigation.
\end{abstract}

Key words: wastewater, waste treatment, DBO, water resources

' Universidade Estadual de Goiás BR 153, 3105, Faz. Barreiro do Meio, CP 459, CEP 75110-390, Anápolis, GO. Fone: (62) 3328-1156. E-mail: erlonalri@gmail.com

${ }^{2}$ Faculdade de Agronomia e Medicina Veterinária/UnB, Campus Universitário Darcy Ribeiro, Instituto Central de Ciências, C.P. 4.508, Ala Sul, Asa Norte, CEP 70910-970, Brasília, DF. Fone: (61) 3701-7570. E-mail: sandri@unb.br

${ }^{3}$ Instituto Federal Goiano Campus Morrinhos. Rod. BR-153, Km 633, Zona Rural. C.P. 92, CEP 75650-000, Morrinhos, GO. Fone: (64) 3413-7900. Fax: (64) 3413-7902. E-mail: josianny.boeno@ifgoiano.edu.br 


\section{INTRODUÇÃO}

De acordo com Sperling (2005) a qualidade da água é resultante de fenômenos naturais, do uso e da ocupação do solo da bacia hidrográfica por atividades humanas neste último caso por interferência antrópica, quer de forma concentrada, como na geração de despejos domésticos ou industriais, ou de forma dispersa, como na aplicação de defensivos agrícolas no solo.

As agroindústrias estão entre as maiores fontes poluidoras no Brasil, particularmente em função das grandes quantidades de resíduos ricos em substâncias orgânicas, nutrientes (sobretudo nitrogênio e fósforo) sólidos, óleos e graxas. Nesta categoria matadouros e indústrias de processamento de carne são conhecidos pelo alto potencial poluidor (Mees et al., 2009). O efluente dos matadouros possui uma elevada vazão e grande carga de sólidos em suspensão, nitrogênio orgânico, além de uma demanda bioquímica de oxigênio - DBO de $4.200 \mathrm{mg} \mathrm{L}^{-1}$ em média (Aguilar et al., 2002) dependendo do reaproveitamento ou do tratamento do efluente. Devido à sua constituição, esses despejos são altamente putrescíveis, iniciando sua decomposição em poucas horas e formando gases, que tornam difícil a respiração nos arredores desses estabelecimentos (Pacheco \& Wolff, 2004).

Os problemas ambientais estão associados ao desenvolvimento socioeconômico o que também se observa na região de Anápolis que, a exemplo do Brasil, vive um momento de grande transformação econômica exigindo, quando do uso dos recursos naturais, maior preocupação. Fato adicional é que o município de Anápolis faz parte do quadro socioeconômico e político do Estado de Goiás, um dos mais importantes, com a segunda posição em economia e a terceira em população. Anápolis é caracterizada como município industrial, haja vista que, além das 657 indústrias distribuídas em seu território, abriga o Distrito Agroindustrial de Anápolis (DAIA), maior polo industrial do estado, com 102 indústrias ativas, 7 em construção e 135 novos projetos aprovados através de incentivos fiscais concedidos pelo estado. Quanto ao efetivo de animais, as aves, com 146.600 cabeças são o principal bem produzido, seguido do efetivo bovino, com 82.000 cabeças. Na Vila Fabril existem olarias, indústria de tijolos, telhas e ladrilhos, mas a base da indústria é de transformação de matérias primas de origem animal e vegetal, como frigoríficos, granjas e benecificiadoras de arroz e feijão (Castro, 2009).

O Córrego Jurubatuba passa margeando o bairro Vila Fabril, onde recebe descarga de esgotos domésticos, de olarias e de um frigorífico. Faz parte da Bacia Hidrográfica do Córrego Lagoinha, afluente do Córrego Catingueiro, tributário do Jurubatuba que, juntamente com o córrego Pedreira, constitui o Ribeirão João Leite, principal manancial responsável pelo abastecimento de água de parte das duas maiores cidade de Goiás, Goiânia e Aparecida de Goiânia. A área da Bacia do Lagoinha possui característica de uso urbano-rural, fato este evidenciado na região de despejo do efluente proveniente de frigorífico, pois existem várias pequenas propriedades instaladas nas margens do Córrego Jurubatuba, voltadas principalmente para a produção de hortaliças (Santos \& Lopes, 2007). Essas propriedades rurais utilizam as águas do córrego e as aplicam por aspersão convencional podendo causar problemas de contaminação nas hortaliças, problemas ao solo e aumentar o risco de doenças, caso essas águas estejam contaminadas pelo efluente do frigorífico e de outras origens.

Ante o exposto objetivou-se avaliar o impacto do lançamento do efluente de abatedouro de bovinos com tratamento secundário sobre as águas de um córrego, assim como avaliar a adequação do efluente ao reúso agrícola, direto e indireto.

\section{Material e Métodos}

A Estação de Tratamento de Efluente - ETE do frigorífico se situa na Vila Fabril, distante $4 \mathrm{~km}$ do centro da cidade de Anápolis, GO, cujas coordenadas geográficas são de $16^{\circ} 22^{\text {' }}$ $22^{\prime \prime}$ de latitude Sul, $48^{\circ} 53^{\prime} 08^{\prime \prime}$ de longitude Oeste e a altitude de $1012 \mathrm{~m}$. O clima da região, de acordo com a classificação de Köppen, apresenta inverno seco e verões quentes e chuvosos. Durante o período seco os valores médios de temperatura máxima, mínima e média, radiação solar diária e velocidade do vento foram de $28,4,17,1$ e $21,9{ }^{\circ} \mathrm{C}, 17,6 \mathrm{MJ} \mathrm{m}^{-2}$ e $6,0 \mathrm{~m} \mathrm{~s}^{-1}$ e no período chuvoso de $26,6,18,6$ e $22,1,{ }^{\circ} \mathrm{C}, 18,1 \mathrm{MJ} \mathrm{m}^{-2} \mathrm{e}$ $6,1 \mathrm{~m} \mathrm{~s}^{-1}$, respectivamente (SIMEGO, 2010).

Todo o efluente gerado no frigorífico é lançado no Córrego Jurubatuba; a quantidade de animais (bovinos) abatidos durante o período seco e chuvoso é apresentada na Figura 1 enquanto na Tabela 1 se encontram a quantidade de cabeças de bovinos abatidos por semana, a quantidade de efluente gerado e o tempo de detenção hidráulica.

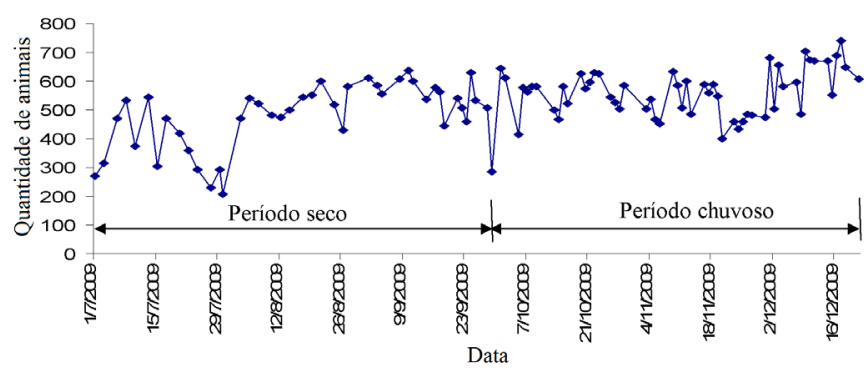

Figura 1. Número de cabeças bovinas abatidas durante o experimento, incluídos o período seco e o chuvoso

A ETE é composta de três lagoas de estabilização em série, das quais duas são anaeróbias com volume útil de 9867,90 e $8107,44 \mathrm{~m}^{3}$, respectivamente, e uma lagoa facultativa com volume útil de 12900,00 $\mathrm{m}^{3}$. Após o tratamento o efluente é lançado no Córrego Jurubatuba, sendo sua menor vazão média determinada de acordo com Bernardo et al. (2006) de $0,195 \mathrm{~m}^{3} \mathrm{~s}^{-1}$, durante o período seco.

A influência do lançamento de efluente tratado de abate de bovinos sobre a qualidade de água do Córrego Jurubatuba, Anápolis, GO, foi realizada pela análise dos seguintes pontos: efluente tratado antes do lançamento no córrego (A), $50 \mathrm{~m}$ à montante (B), $50 \mathrm{~m}(\mathrm{C})$ e $500 \mathrm{~m}$ (D) à jusante do ponto de lançamento do efluente no córrego.

Coletaram-se amostras nos dias 9 e 15 de julho, 21 e 28 de agosto, 4, 11, 18 e 25 de setembro de 2009, caracterizando o período seco e, nos dias 2, 16, 23 e 28 de outubro, 6,13 e 19 de novembro e 4 de dezembro, como referentes ao período chuvoso; as coletas foram realizadas entre 8 e $9 \mathrm{~h}$. 
Tabela 1. Quantidade de cabeças de gado abatidas por semana, quantidade de efluente gerado na estação de tratamento de efluente (ETE) e tempo de detenção hidráulica no período seco

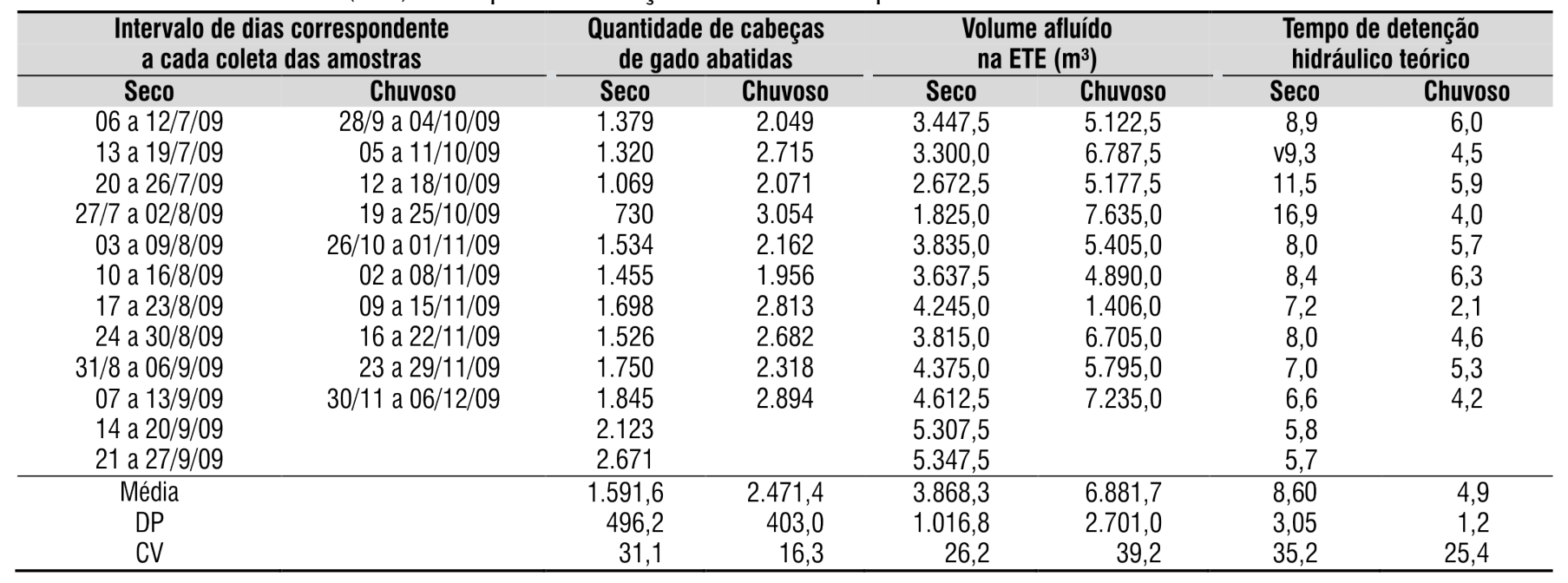

As amostras de efluente foram armazenadas em garrafas esterilizadas de $2 \mathrm{~L}$ e transportadas em caixa de isopor até o Laboratório de Química Analítica da Unidade Universitária de Ciências Exatas e Tecnológicas - UnUCET, da Universidade Estadual de Goiás - UEG.

Quantificaram-se os valores de $\mathrm{pH}$, turbidez, oxigênio dissolvido, saturação de oxigênio, carbono orgânico total, cloro, alumínio, amônia, cobre, manganês, ferro total, fósforo total, sulfeto, sódio, DBO, DQO, nitrogênio total, condutividade elétrica, nitrato, nitrito e alcalinidade, determinados seguindose metodologias apresentadas em APHA (1995).

A análise dos dados foi feita pela comparação das médias pelo teste Tukey, com nível mínimo de significância de 5 \% (P $<0,05)$ utilizando-se o software Statistica 6.0.

\section{Resultados E Discussão}

Os dados obtidos da análise do efluente tratado e da água do córrego Jurubatuba para os parâmetros DBO, DQO, turbidez, oxigênio dissolvido, carbono orgânico total, nitrogênio total, nitrato e nitrito, são apresentados na Tabela 2.

A água analisada no ponto B do córrego Jurubatuba se enquadra como classe 2 (Brasil, 2005), isto é, pode ser utilizada água para abastecimento visando ao consumo humano podendo ser usado, também, após tratamento convencional para proteção das comunidades aquáticas e à recreação de contato primário, tais como, natação esqui aquático e mergulho.

Demanda biológica de oxigênio: $\mathrm{O}$ efluente tratado (ponto $\mathrm{A}$ ) apresentou maior valor de $\mathrm{DBO}$ em relação a $50 \mathrm{~m}$ à montante e maior em relação a 50 e $500 \mathrm{~m}$ à jusante do lançamento do efluente no período seco; já 50 m à jusante no período chuvoso, foi maior em relação ao período seco. Verifica-se, nos pontos à jusante do lançamento do efluente, aumento de DBO no período seco em razão do lançamento do efluente no córrego. No período chuvoso a DBO apresentou, nos três pontos analisados no córrego, teores bem mais elevados em relação ao período seco (Tabela 2) embora não significativo devido, provavelmente, às precipitações que ocorreram neste período, de até $17,3 \mathrm{~mm}$ ao dia, elevando a quantidade de matéria orgânica na água.
Mesmo com a bacia hidrográfica preservada, a qualidade das águas é afetada pelo escoamento superficial e pela infiltração no solo, resultantes da precipitação atmosférica. A incorporação de sólidos em suspensão ou oriundos da dissolução de rochas ocorre naturalmente (Sperling, 2005).

Constata-se que os valores de DBO do efluente nos dois períodos analisados foram menores aos obtidos por José et al. (2009) em efluente de abatedouro bovino tratado em lagoas de estabilização e aplicado na irrigação da cultura do milho (641 $\mathrm{mg} \mathrm{L}{ }^{-1}$ ). Já Machado et al. (2005) observaram valores de DBO de $15,57 \mathrm{mg} \mathrm{L}^{-1}$ na água do rio Paraibuna, próximo a Juiz de Fora, MG, bem inferiores aos obtidos na água do córrego deste trabalho, em ambos os períodos, chegando a $276,16 \mathrm{mg} \mathrm{L}^{-1}$ no período chuvoso a $50 \mathrm{~m}$ à jusante do ponto de lançamento, tornando-se maior neste ponto, em virtude do efeito combinado da chuva e do lançamento do efluente.

Em Brasil (2011) foi determinado que, para o lançamento de efluente tratado, a remoção de DBO deve apresentar no mínimo $60 \%$, sendo que este limite só poderá ser reduzido no caso de existência de estudo de autodepuração do corpo hídrico que comprove atendimento às metas do enquadramento do corpo receptor. Foram coletadas amostras do efluente bruto, nos períodos seco e chuvoso, os quais apresentaram remoção de 69 e $67 \%$, respectivamente.

Demanda química de oxigênio: Observa-se que, no período seco, a DQO do efluente foi maior em relação aos pontos analisados no córrego enquanto no período chuvoso todos os pontos analisados diferiram entre si, cujo maior valor foi obtido no efluente tratado. A exemplo da DBO e mesmo com valores bastante diferentes entre os períodos seco e chuvoso, não se observou diferença significativa influenciado, em parte, pelo elevado coeficiente de variação entre as repetições, chegando a mais de $183 \%$. A grande variação entre as amostras é uma característica comum em efluentes de estações de tratamento, independente do tipo de afluente a ser tratado, como obtido por Igbinosa \& Okoh (2009) em efluente doméstico tratado em uma ETE constituída por uma série de lagoas de estabilização (34,82 a 238,00 $\left.\mathrm{mg} \mathrm{L}^{-1}\right)$. 
Tabela 2. Valores médios* de DBO, DQO, turbidez, oxigênio dissolvido, carbono orgânico total, nitrogênio total, nitrato e nitrito no efluente e água do córrego Jurubatuba

\begin{tabular}{|c|c|c|c|c|c|c|c|c|c|}
\hline \multirow[b]{2}{*}{ Parâmetro } & \multirow{2}{*}{$\begin{array}{c}\text { Pontos } \\
\text { de } \\
\text { coleta* }^{* *}\end{array}$} & \multicolumn{4}{|c|}{ Período seco } & \multicolumn{4}{|c|}{ Período chuvoso } \\
\hline & & Valores & $\begin{array}{c}- \text { red. e + } \\
\text { ele. (\%) }\end{array}$ & DP & $\begin{array}{l}\text { CV } \\
(\%)\end{array}$ & Valores & $\begin{array}{c}- \text { red. e + } \\
\text { ele. (\%) }\end{array}$ & DP & $\begin{array}{l}\text { CV } \\
(\%)\end{array}$ \\
\hline \multirow{4}{*}{$\begin{array}{c}\mathrm{DBO} \\
\left(\mathrm{mg} \mathrm{L}^{-1}\right)\end{array}$} & A & 75,54 bA & $+84,5$ & 37,29 & 49,37 & $89,80 \mathrm{aA}$ & $-41,5$ & 54,63 & 60,83 \\
\hline & B & $40,93 \mathrm{cB}$ & - & 26,79 & 65,45 & $153,61 \mathrm{aA}$ & - & 145,78 & 94,89 \\
\hline & $\mathrm{C}$ & $87,08 \mathrm{aA}$ & $+112,7$ & 32,41 & 38,09 & $276,16 \mathrm{aA}$ & $+79,7$ & 324,41 & 117,47 \\
\hline & D & 86,21 aA & $+110,6$ & 36,57 & 42,42 & $145,12 \mathrm{aA}$ & $-5,5$ & 157,09 & 108,24 \\
\hline \multirow{4}{*}{$\begin{array}{c}\mathrm{DQO} \\
\left(\mathrm{mg} \mathrm{L}^{-1}\right)\end{array}$} & A & $505,99 \mathrm{aA}$ & $+2776,5$ & 179,97 & 35,56 & $341,92 \mathrm{aA}$ & $+318,7$ & 140,82 & 41,18 \\
\hline & B & $17,59 \mathrm{bA}$ & - & 32,33 & 183,78 & $81,65 \mathrm{cA}$ & - & 136,84 & 173,45 \\
\hline & $\mathrm{C}$ & $165,04 \mathrm{bA}$ & $+838,2$ & 301,68 & 173,18 & $114,14 \mathrm{bA}$ & $+39,7$ & 155,02 & 135,81 \\
\hline & D & $90,53 \mathrm{bA}$ & $+414,6$ & 68,58 & 81,39 & $48,19 \mathrm{dA}$ & $-40,1$ & 56,43 & 117,10 \\
\hline \multirow{4}{*}{$\begin{array}{l}\text { Turbidez } \\
\text { (NTU) }\end{array}$} & A & $118,15 \mathrm{aA}$ & $+1833,7$ & 9,75 & 8,25 & $100,19 \mathrm{aA}$ & $+283,8$ & 28,48 & 28,42 \\
\hline & B & $6,11 \mathrm{aA}$ & - & 4,63 & 75,64 & $26,10 \mathrm{aA}$ & - & 31,96 & 122,48 \\
\hline & C & $24,13 \mathrm{aA}$ & $+294,9$ & 8,76 & 66,59 & $166,71 \mathrm{aA}$ & $+538,7$ & 287,65 & 172,54 \\
\hline & D & $44,82 \mathrm{aA}$ & $+633,5$ & 5,57 & 50,10 & $164,40 \mathrm{aA}$ & $+529,8$ & 288,54 & 175,51 \\
\hline \multirow{4}{*}{$\begin{array}{l}\text { Oxigênio } \\
\text { Dissolvido } \\
\left(\mathrm{mg} \mathrm{L}^{-1}\right)\end{array}$} & A & $2,29 \mathrm{bA}$ & $-61,4$ & 2,29 & 78,90 & $0,86 \mathrm{bA}$ & $-82,0$ & 0,91 & 106,11 \\
\hline & B & $5,94 \mathrm{bA}$ & - & 5,94 & 20,01 & $4,78 \mathrm{aA}$ & - & 1,31 & 27,48 \\
\hline & C & $5,19 \mathrm{abA}$ & $-12,6$ & 5,19 & 14,43 & $4,54 \mathrm{aA}$ & $-5,0$ & 1,43 & 31,53 \\
\hline & D & $5,54 \mathrm{aA}$ & $-6,7$ & 5,54 & 22,31 & $4,71 \mathrm{aA}$ & $-1,4$ & 4,57 & 96,90 \\
\hline \multirow{4}{*}{$\begin{array}{l}\text { Carbono } \\
\text { Orgânico Total } \\
\left(\mathrm{mg} \mathrm{L}^{-1}\right)\end{array}$} & A & $150,09 \mathrm{aA}$ & $+426,4$ & 21,24 & 14,15 & $136,41 \mathrm{aA}$ & $+405,5$ & 23,38 & 17,13 \\
\hline & B & $28,51 \mathrm{aA}$ & - & 2,38 & 8,33 & $26,98 \mathrm{aA}$ & - & 3,06 & 11,34 \\
\hline & C & $35,82 \mathrm{aA}$ & $+25,6$ & 3,49 & 15,05 & 20,92 bA & $-22,4$ & 3,28 & 15,68 \\
\hline & D & 57,10 aA & $+100,2$ & 2,40 & 12,47 & $27,21 \mathrm{aB}$ & $+0,8$ & 2,48 & 9,11 \\
\hline \multirow{4}{*}{$\begin{array}{l}\text { Nitrogênio Total } \\
\left(\mathrm{mg} \mathrm{L}^{-1}\right)\end{array}$} & $A$ & $1,53 \mathrm{aA}$ & $-69,9$ & 1,22 & 79,75 & $0,51 \mathrm{aA}$ & $-90,3$ & 0,74 & 145,91 \\
\hline & B & $5,09 \mathrm{aA}$ & - & 2,11 & 41,56 & $5,28 \mathrm{aA}$ & -1 & 1,99 & 37,77 \\
\hline & C & 6,65 aA & $+30,6$ & 2,73 & 41,05 & $7,14 \mathrm{aA}$ & $+35,2$ & 6,50 & 91,07 \\
\hline & D & $5,60 \mathrm{aA}$ & $+10,0$ & 2,74 & 48,91 & $4,13 \mathrm{aA}$ & $+21,7$ & 3,00 & 72,64 \\
\hline \multirow{4}{*}{$\begin{array}{l}\text { Nitrato } \\
\left(\mathrm{mg} \mathrm{L}^{-1}\right)\end{array}$} & $A$ & $4,11 \mathrm{bA}$ & $-35,8$ & 1,88 & 51,10 & $2,44 \mathrm{aA}$ & $-41,7$ & 0,84 & 38,37 \\
\hline & B & $6,41 \mathrm{bA}$ & - & 2,91 & 52,81 & $4,19 \mathrm{aA}$ & - & 5,90 & 104,24 \\
\hline & C & $7,79 \mathrm{abA}$ & $+21,5$ & 3,95 & 60,21 & $7,38 \mathrm{aA}$ & $+76,1$ & 6,88 & 81,88 \\
\hline & D & $6,69 \mathrm{aA}$ & $+4,3$ & 1,74 & 41,58 & $7,15 \mathrm{aA}$ & $+70,6$ & 11,11 & 104,53 \\
\hline \multirow{4}{*}{$\left(\mathrm{mg} \mathrm{L}^{-1}\right)$} & $A$ & $0,23 \mathrm{bA}$ & $+64,2$ & 0,14 & 67,67 & $0,15 \mathrm{aA}$ & $+15,3$ & 0,29 & 113,77 \\
\hline & B & $0,14 \mathrm{bA}$ & - & 0,14 & 102,25 & $0,13 \mathrm{aA}$ & - & 0,32 & 116,06 \\
\hline & C & $0,33 \mathrm{abA}$ & $+135,7$ & 0,15 & 51,53 & $0,33 \mathrm{aA}$ & $+153,8$ & 0,28 & 88,28 \\
\hline & D & $0,32 \mathrm{aA}$ & $+128,5$ & 0,14 & 68,76 & $0,32 \mathrm{aA}$ & $+146,1$ & 0,28 & 83,72 \\
\hline \multirow{4}{*}{$\begin{array}{l}\text { Amônia } \\
\left(\mathrm{mg} \mathrm{L}^{-1}\right)\end{array}$} & A & $0,43 \mathrm{bB}$ & $+437,5$ & 0,66 & 154,13 & $1,42 \mathrm{abA}$ & $+992,3$ & 0,58 & 48,23 \\
\hline & B & $0,08 \mathrm{bA}$ & - & 0,14 & 173,87 & $0,13 \mathrm{bcA}$ & - & 0,18 & 135,98 \\
\hline & C & $0,70 a b A$ & $+775,0$ & 0,70 & 56,53 & $1,91 \mathrm{abA}$ & $+1369,2$ & 0,84 & 48,13 \\
\hline & $\mathrm{D}$ & $0,63 \mathrm{aA}$ & $+687,5$ & 0,63 & 68,23 & $1,98 \mathrm{aA}$ & $+1423,0$ & 0,67 & 38,69 \\
\hline
\end{tabular}

* Médias seguidas de letras minúscula distintas nas colunas, diferem entre os pontos de análise no mesmo período de coleta e letras maiúsculas na linha diferem entre os períodos em cada ponto de análise, a nível de 0,05 pelo teste de Tukey. red.: redução; ele.: elevação. DP: Desvio Padrão; CV: coeficiente de variação. Valores: média de 8 repetições.

${ }^{\star *} \mathrm{~A}$ : efluente tratado antes do lançamento no córrego, B: $50 \mathrm{~m}$ à montante, C: $50 \mathrm{~m}$ e D: $500 \mathrm{~m}$ à jusante do ponto de lançamento do efluente no córrego Jurubatuba

Obteve-se, no período seco, valor médio de $505,99 \mathrm{mg} \mathrm{L}^{-1}$ e no período chuvoso de $341,92 \mathrm{mg} \mathrm{L}^{-1}$, inferiores aos obtidos por José et al. (2009) em efluente de abatedouro bovino tratado em lagoas de estabilização $\left(789,0 \mathrm{mg} \mathrm{L}^{-1}\right)$ ressaltando a grande quantidade de matéria orgânica presente em águas residuárias de abate bovino.

Nesses dois períodos o efluente lançado provocou aumento nas concentrações de DQO nas águas do córrego. Além disto, à medida em que os resíduos se afastam do local de lançamento, as concentrações começam a diminuir, de acordo com Sperling (2005).

Turbidez: A turbidez do efluente lançado no córrego, nos dois períodos, provocou a elevação da sua turbidez. Na resolução 430/2011 não foram feitas ressalvas quanto aos valores de turbidez. Segundo Brasil (2005) o máximo permitido para a água de classe 2 é de 100 NTU; assim, somente o ponto A, no período seco e nos pontos $\mathrm{C} \mathrm{e} \mathrm{D}$, período chuvoso, não atendeu à legislação.

Bonnet et al. (2008) avaliaram 89 pontos nas bacias hidrográficas no Estado de Goiás encontrando valores médios de turbidez no período seco, de 8,72 NTU e, no período chuvoso, de 54,57 NTU, inferiores aos obtidos neste trabalho.

Embora se observe grande diferença entre os valores, tanto entre os pontos analisados como entre os períodos, não se constatou variação significativa já que o coeficiente de variação foi muito elevado.

Oxigênio dissolvido: Observa-se, em ambos os períodos, que o efluente lançado no córrego influenciou as concentrações de oxigênio dissolvido, com diminuição de seu valor (Tabela 2). Em Brasil (2011) a Resolução 430 não estabalece novos valores 
para o oxigênio dissolvido sendo assim, os valores comparados foram da Resolução 357/2005 que estabelece o limite mínimo de $5 \mathrm{mg} \mathrm{L}^{-1}$ de OD; desta maneira, apenas os três pontos analisados no córrego, no período seco, atenderam à legislação. O oxigênio dissolvido não é apenas essencial para os organismos aeróbios mas também o principal parâmetro de caracterização dos efeitos da poluição das águas por despejos orgânicos. Durante a estabilização da matéria orgânica as bactérias utilizam oxigênio em seus processos respiratórios, podendo reduzir sua concentração nos esgotos tratados ou em cursos d'água (Sperling, 2005). Este efeito foi constatado neste trabalho e também por Thebaldi et al. (2010) que, estudando a qualidade da água de um córrego sob influência de efluente tratado de abate bovino, também encontraram valores de oxigênio dissolvido dentro da faixa permitida pela Resolução 357/2005.

Carbono orgânico total (COT): $\mathrm{Na}$ concentração de COT no período chuvoso, ocorreu diferença nas médias indicando que a descarga de poluente aumentou a concentração na água do córrego (Tabela 2). Ainda neste mesmo período o ponto $\mathrm{C}$ provocou um ligeiro aumento da concentração de COT sendo que a concentração de efluente, ponto $\mathrm{A}$, foi $400 \%$ maior que as do córrego, antes do ponto de lançamento (ponto B). Em contrapartida, no período seco os pontos B, C e D não diferem significativamente.

Nitrogênio total: Embora sendo os valores de nitrogênio total no ponto $\mathrm{A}$, períodos seco e chuvoso, menores que os dos pontos $\mathrm{B}$, nota-se claramente que o despejo não provocou um aumento significativo nas concentrações de nitrogênio total, nos pontos à jusante (Tabela 2). Os teores de nitrogênio total no córrego no período chuvoso não apresentaram diferença significativa em comparação com o período seco. Apenas houve um pequeno aumento que pode ser explicado devido ao arraste de sedimentos ao córrego pela água da chuva (Sperling, 2005).

Mansor et al. (2006) observaram, ao avaliar a influência da atividade rural sobre a qualidade da água do rio Jaguari, durante seis anos, valor mínimo e máximo de concentração de nitrogênio total de 0,35 e $4,5 \mathrm{mg} \mathrm{L}^{-1}$, respectivamente. A prática do plantio direto e o sistema de terraceamentos existentes nas áreas agricultáveis, também justificam tais resultados fato passível de explicar as maiores concentrações de nitrogênio total nas águas do córrego em relação ao efluente lançado uma vez que existem, ao redor do córrego, várias plantações de hortaliças, nas quais os agricultores fazem uso constante de fertilizantes à base de nitrogênio e fósforo.

Nitrato: Apenas no período seco o valor do efluente lançado no ponto A contribuiu para a elevação da concentração de nitrato nos pontos, à jusante (Tabela 2). Queiroz et al. (2010), encontraram, estudando a bacia hidrográfica no município de Cascavel, PR, valores de nitrato de $1,1 \mathrm{mg} \mathrm{L}^{-1}$. Vivan et al. (2010) afirmaram que lagoas de estabilização facultativa possuem elevada capacidade de remoção de nitrogênio devido ao processo de volatilização e às grandes áreas superficiais.

Nitrito: No período seco o teor de nitrito no ponto de coleta $\mathrm{D}$ foi maior nos pontos de coleta A e B (Tabela 2). Em Brasil
(2011) não foram feitas ressalvas quanto aos valores de nitrito permanecendo assim os valores limites determinados em Brasil (2005). Com relação a eles, todos os pontos de coleta nos dois períodos apresentaram valores menores que os limites indicados para qualidade de corpos hídricos de classe $2\left(1,0 \mathrm{mg} \mathrm{L}^{-1}\right)$. Os pontos de coleta $\mathrm{C}$ e $\mathrm{D}$ foram, nos dois períodos de análise, maiores aos obtidos por Rabelo et al. (2009) nas águas do Ribeirão João Leite, próximo a Goiânia, $\mathrm{GO}\left(0,2 \mathrm{mg} \mathrm{L}^{-1}\right)$ que recebe efluente urbano.

No período seco verificou-se que os despejos favoreceram o aumento das concentrações de nitrito no córrego nos pontos $\mathrm{C}$ e D mas começam a reduzir com a autodepuração natural no córrego (Sperling, 2005).

Amônia: O teor de amônia no período seco no ponto de coleta $\mathrm{D}$ foi maior nos pontos $\mathrm{A}$ e $\mathrm{B}$, enquanto no período chuvoso foi maior somente em relação ao ponto B (Tabela 2). Observa-se ainda que no período chuvoso os teores foram mais elevados que no período seco porém com diferença significativa apenas no ponto A.

Carvalho et al. (2004) encontraram, estudando a qualidade das águas do Ribeirão Ubá, MG, valores de amônia, em um dia chuvoso, de 0,05 a 4,21 $\mathrm{mg} \mathrm{L}^{-1}$ superiores, portanto, aos resultados encontrados.

O lançamento do efluente de abate de bovinos elevou os teores de amônia no córrego Jurubatuba. Brasil (2005) estabeleceu como padrão de qualidade de corpos hídricos classe 2, concentração máxima de $5,6 \mathrm{mg} \mathrm{L}^{-1}$ de nitrogênio amoniacal em faixa de $\mathrm{pH}$ entre 7,5 e 8,0 e para lançamento de efluentes Brasil (2011) determinou não mais que $20 \mathrm{mg} \mathrm{L}^{-1}$, condições presentes nos pontos avaliados.

$\mathrm{Na}$ Tabela 3 são apresentados os valores médios de $\mathrm{pH}$, cloro, alumínio, cobre, zinco, ferro total, manganês, fósforo, sódio e condutividade elétrica do efluente de abate de bovinos tratado.

pH: Os valores de $\mathrm{pH}$ no período seco não apresentaram diferença significativa. Os pontos dos córregos B, C e D apresentaram os mesmos valores, conforme a Tabela 3 . No período chuvoso, devido à quantidade de sedimentos levantados do fundo do córrego, o escoamento superficial foi acentuado (Sperling, 2005). A quantidade de matéria orgânica aumentou, favorecendo a redução dos valores de $\mathrm{pH}$.

Donadio et al. (2005) encontraram, estudando o Rio Rico, entre Taquaritinga e Guariba, SP, valores de $\mathrm{pH}$ entre 6 e 7, nos períodos seco e chuvoso, aproximando-se dos valores encontrados.

Palácio et al. (2009) constataram, estudando qualidade das águas superficiais da bacia do Curu, Ceará, valores médios de $\mathrm{pH}$ entre 7,27 a 7,66, semelhantes aos encontrados no córrego Jurubatuba, em ambos os períodos. A Resolução Conama 430/2011 estabelece $\mathrm{pH}$ entre 5 a 9.

Cloro: Observou-se presença de cloro na água do córrego no período seco, embora em baixa concentração explicado, em parte, pela ação antrópica nas suas margens, como descarga de esgoto doméstico, de forma irregular (Tabela 3). Arraes (2009) também acreditou, em um estudo realizado nas águas 
Tabela 3. Valores médios* de $\mathrm{pH}$, cloro, alumínio, cobre, ferro total, manganês, fósforo, sódio e condutividade elétrica do efluente de abate de bovinos tratado, em diferentes pontos de coleta no córrego Jurubatuba

\begin{tabular}{|c|c|c|c|c|c|c|c|c|c|}
\hline \multirow[b]{2}{*}{ Parâmetro } & \multirow{2}{*}{$\begin{array}{l}\text { Pontos } \\
\text { de } \\
\text { coleta* }^{* *}\end{array}$} & \multicolumn{4}{|c|}{ Período seco } & \multicolumn{4}{|c|}{ Período chuvoso } \\
\hline & & Valores & $\begin{array}{c}\text { - red. e + } \\
\text { ele. (\%) }\end{array}$ & DP & $\begin{array}{l}\text { CV } \\
\text { (\%) }\end{array}$ & Valores & $\begin{array}{c}\text { - red. e + } \\
\text { ele. (\%) }\end{array}$ & DP & $\begin{array}{l}\text { CV } \\
\text { (\%) }\end{array}$ \\
\hline \multirow{4}{*}{$\mathrm{pH}$} & A & $7,70 \mathrm{aA}$ & $+1,58$ & 0,22 & 2,81 & $7,50 \mathrm{aA}$ & $+3,3$ & 0,20 & 2,71 \\
\hline & B & 7,58 aA & - & 0,58 & 7,60 & $7,26 \mathrm{aA}$ & - & 0,46 & 6,38 \\
\hline & C & $7,58 \mathrm{aA}$ & 0,0 & 0,19 & 2,56 & $7,41 \mathrm{aA}$ & $+2,0$ & 0,27 & 3,62 \\
\hline & D & $7,58 \mathrm{aA}$ & 0,0 & 0,23 & 2,98 & $7,32 \mathrm{aA}$ & $+0,8$ & 0,30 & 4,14 \\
\hline \multirow{4}{*}{$\begin{array}{l}\text { Cloro } \\
\left(\mathrm{mg} \mathrm{L}^{-1}\right)\end{array}$} & A & $1,84 \mathrm{abA}$ & $+2200,0$ & 0,19 & 10,33 & $1,39 \mathrm{aB}$ & $+308,8$ & 0,23 & 16,40 \\
\hline & B & $0,08 \mathrm{bA}$ & - & 0,05 & 61,23 & $0,34 \mathrm{aA}$ & - & 0,49 & 146,84 \\
\hline & C & $0,25 \mathrm{abA}$ & $+212,5$ & 0,16 & 63,18 & $0,52 \mathrm{aA}$ & $+52,9$ & 0,40 & 76,34 \\
\hline & D & $0,22 \mathrm{aA}$ & $+175,0$ & 0,11 & 49,90 & $0,37 \mathrm{aA}$ & $+8,8$ & 0,34 & 90,92 \\
\hline \multirow{4}{*}{$\begin{array}{l}\text { Alumínio } \\
\left(\mathrm{mg} \mathrm{L}^{-1}\right)\end{array}$} & A & $0,35 \mathrm{bA}$ & $+3400,0$ & 0,14 & 39,06 & $0,26 \mathrm{aA}$ & $+550,0$ & 0,09 & 33,96 \\
\hline & B & $0,01 \mathrm{bA}$ & - & 0,02 & 182,45 & $0,04 \mathrm{aA}$ & - & 0,20 & 247,72 \\
\hline & C & $0,04 \mathrm{abA}$ & $+300,0$ & 0,03 & 79,28 & $0,05 \mathrm{aA}$ & $+25,0$ & 0,12 & 233,65 \\
\hline & D & $0,03 \mathrm{aA}$ & $+200,0$ & 0,02 & 80,34 & $0,06 \mathrm{aA}$ & $+50,0$ & 0,15 & 237,88 \\
\hline \multirow{4}{*}{$\begin{array}{l}\text { Cobre } \\
\left(\mathrm{mg} \mathrm{L}^{-1}\right)\end{array}$} & A & $1,36 \mathrm{bA}$ & $+81,3$ & 2,41 & 177,72 & $0,92 \mathrm{aA}$ & $+35,2$ & 0,97 & 105,55 \\
\hline & B & $0,75 \mathrm{bA}$ & - & 0,60 & 80,58 & $0,68 \mathrm{aA}$ & - & 0,90 & 132,12 \\
\hline & C & $0,68 \mathrm{aA}$ & $-9,3$ & 0,68 & 91,64 & $0,63 \mathrm{aA}$ & $-7,3$ & 0,95 & 150,15 \\
\hline & D & $1,19 \mathrm{aA}$ & $+58,6$ & 1,19 & 105,38 & $0,71 \mathrm{aA}$ & $+4,41$ & 0,99 & 138,98 \\
\hline \multirow{4}{*}{$\begin{array}{l}\text { Ferro total } \\
\left(\mathrm{mg} \mathrm{L}^{-1}\right)\end{array}$} & $A$ & $2,49 \mathrm{abA}$ & $+1210,5$ & 0,61 & 24,53 & $1,63 \mathrm{aA}$ & $+239,5$ & 0,45 & 27,77 \\
\hline & B & $0,19 \mathrm{bA}$ & - & 0,14 & 71,26 & $0,48 \mathrm{aA}$ & - & 0,78 & 160,35 \\
\hline & C & $0,27 \mathrm{abA}$ & $+42,1$ & 0,27 & 64,37 & $0,48 \mathrm{aA}$ & 0,0 & 0,74 & 154,77 \\
\hline & D & $0,15 \mathrm{aA}$ & $-21,0$ & 0,16 & 56,25 & $0,42 \mathrm{aA}$ & $-12,5$ & 0,60 & 144,03 \\
\hline \multirow{4}{*}{$\begin{array}{l}\text { Manganês } \\
\left(\mathrm{mg} \mathrm{L}^{-1}\right)\end{array}$} & A & $1,91 \mathrm{aA}$ & $+516,1$ & 0,65 & 33,92 & $1,53 \mathrm{aA}$ & $+665,0$ & 0,77 & 50,00 \\
\hline & B & $0,31 \mathrm{aA}$ & - & 0,52 & 164,14 & $0,20 \mathrm{bA}$ & - & 0,30 & 148,54 \\
\hline & C & $0,20 \mathrm{aA}$ & $-35,4$ & 0,14 & 70,46 & $0,29 \mathrm{bA}$ & $+45,0$ & 0,42 & 141,91 \\
\hline & D & $0,20 \mathrm{aA}$ & $-35,4$ & 0,04 & 18,63 & $0,23 \mathrm{bA}$ & $+15,0$ & 0,37 & 159,48 \\
\hline \multirow{4}{*}{$\begin{array}{l}\text { Fósforo } \\
\left(\mathrm{mg} \mathrm{L}^{-1}\right)\end{array}$} & A & $12,35 \mathrm{aA}$ & $+4016,6$ & 5,58 & 45,19 & $7,77 \mathrm{aA}$ & $+1553,1$ & 4,29 & 55,14 \\
\hline & B & $0,30 \mathrm{aA}$ & - & 0,18 & 61,89 & $0,47 \mathrm{bA}$ & - & 0,44 & 92,52 \\
\hline & C & $1,70 \mathrm{aA}$ & $+466,6$ & 0,89 & 51,62 & $1,41 \mathrm{bA}$ & $+200,0$ & 1,02 & 72,67 \\
\hline & D & $1,02 \mathrm{aA}$ & $+240,0$ & 0,32 & 31,68 & $0,94 \mathrm{bA}$ & $+100,0$ & 0,81 & 86,59 \\
\hline \multirow{4}{*}{$\begin{array}{l}\text { Sódio } \\
\left(\mathrm{mg} \mathrm{L}^{-1}\right)\end{array}$} & A & $197,50 \mathrm{aA}$ & $+1355,4$ & 18,69 & 9,46 & $189,38 \mathrm{aA}$ & $+1571,4$ & 51,70 & 27,29 \\
\hline & B & $13,57 \mathrm{bA}$ & - & 0,51 & 3,77 & $11,33 \mathrm{bA}$ & - & 2,82 & 24,91 \\
\hline & C & $26,14 \mathrm{bA}$ & $+92,6$ & 11,61 & 44,44 & $27,12 \mathrm{bA}$ & $+139,3$ & 10,29 & 37,95 \\
\hline & D & 14,52 bA & $+7,0$ & 1,37 & 9,43 & $17,34 \mathrm{bA}$ & $+53,0$ & 5,64 & 32,52 \\
\hline \multirow{4}{*}{$\begin{array}{l}\text { Condutividade } \\
\text { Elétrica } \\
\left(\mathrm{dS} \mathrm{m}^{-1}\right)\end{array}$} & $A$ & $2,31 \mathrm{aA}$ & $+755,5$ & 0,34 & 14,73 & $1,96 \mathrm{aA}$ & $+653,8$ & 0,74 & 37,76 \\
\hline & B & $0,27 \mathrm{bA}$ & - & 0,07 & 26,09 & $0,26 \mathrm{bA}$ & - & 0,06 & 22,55 \\
\hline & C & $0,44 \mathrm{abA}$ & $+62,9$ & 0,09 & 21,64 & $0,46 \mathrm{bA}$ & $+76,9$ & 0,13 & 28,13 \\
\hline & D & $0,38 \mathrm{abA}$ & $+40,7$ & 0,04 & 10,51 & $0,33 \mathrm{bA}$ & $+26,9$ & 0,10 & 29,81 \\
\hline
\end{tabular}

* Médias seguidas de letras minúscula distintas nas colunas diferem entre os pontos de análise no mesmo período de coleta e letras maiúsculas na linha diferem entre os períodos em cada ponto de análise, a nível de 0,05 pelo teste de Tukey. red.: redução; ele.: elevação. DP: Desvio Padrão; CV: coeficiente de variação. Valores: média de 8 repetições.

** A: efluente tratado antes do lançamento no córrego, B: $50 \mathrm{~m}$ à montante, C: $50 \mathrm{~m}$ e D: $500 \mathrm{~m}$ à jusante do ponto de lançamento do efluente no córrego Jurubatuba

superficiais do rio Trussu, que a presença de cloreto nas águas superficiais fosse decorrente de ação antrópica (deposição de esgotos domésticos e a lavagem de roupas nessas águas). CETESB (2010) afirmou que as descargas de esgotos sanitários são fontes importantes de cloreto nas águas superficiais sendo que cada pessoa expele, através da urina, cerca $6 \mathrm{~g}$ de cloreto por dia, o que faz com que os esgotos apresentem concentrações de cloreto que ultrapassam a $15 \mathrm{mg} \mathrm{L}^{-1}$, da mesma forma que o sulfato. Sabe-se que o cloreto também interfere no tratamento anaeróbio de efluentes industriais, podendo chegar a provocar corrosão em tubulações. No período chuvoso não foi constatada, em nenhum dos pontos, diferença significativa.

Alumínio: No período seco somente o ponto D apresentou diferença significativa em relação aos demais pontos, quanto aos teores de alumínio (Tabela 3). No período chuvoso não houve diferença significativa podendo ser explicado pelo aumento do número de animais abatidos. De maneira geral, o lançamento de efluente em ambos os períodos estudados, elevou a concentração de alumínio na água do córrego.

O alumínio na água pode ocorrer em diferentes formas e é influenciado pelo $\mathrm{pH}$, temperatura e presença de fluoretos, sulfatos, matéria orgânica e outros ligantes, cuja solubilidade é baixa em $\mathrm{pH}$ entre 5,5 e 6,0. As concentrações de alumínio dissolvido em águas com $\mathrm{pH}$ neutro, variam de 0,001 a 0,05 $\mathrm{mg} \mathrm{L}^{-1}$ mas aumentam para $0,5 \mathrm{a} 1 \mathrm{mg} \mathrm{L}^{-1} \mathrm{em}$ águas mais ácidas ou ricas em matéria orgânica (CETESB, 2010). Como o pH da água do córrego nos pontos $\mathrm{B}, \mathrm{C}$ e D ficou próximo, em ambos os períodos, da neutralidade, verificou-se que a solubilidade do alumínio foi próxima dos $0,05 \mathrm{mg} \mathrm{L}^{-1}$. 
Segundo CETESB (2010) o aumento da concentração de alumínio está associado ao período de chuvas e, portanto, com a alta turbidez. Por outro lado e analisando o ponto B, período chuvoso, nota-se um acréscimo na concentração com relação ao mesmo ponto no período seco; entretanto, no período chuvoso não se constatou diferença significativamente entre os pontos.

A Portaria n. 518/2004 (Brasil, 2004) estabelece, para o alumínio, valor máximo permitido de $0,2 \mathrm{mg} \mathrm{L}^{-1}$ como padrão de aceitação para a água de consumo humano. Brasil (2005) determinou, para um rio de classe 2, limite máximo de $0,1 \mathrm{mg} \mathrm{L}^{-1}$ de alumínio; assim, em ambos os períodos as concentrações não ultrapassaram este valor.

Cobre: Os pontos A e B apresentaram diferença significativa em comparação com os pontos $\mathrm{C}$ e D no período seco. Em contrapartida, todos os pontos do período chuvoso não apresentaram valores que expressassem alguma diferença na comparação das médias. A Resolução CONAMA n. 357/2005 (Brasil, 2005) determinou que o valor máximo de cobre para um rio de Classe 1 e 2, seja de 0,009 $\mathrm{mg} \mathrm{L}^{-1}$ e em Brasil (2011) determinou que o lançamento permitido de um efluente contivesse no máximo $1,0 \mathrm{mg} \mathrm{L}^{-1}$ de cobre. Estudos indicam que uma concentração de $20 \mathrm{mg} \mathrm{L}^{-1}$ de cobre ou um teor total de $100 \mathrm{mg} \mathrm{L}^{-1}$ por dia na água, é capaz de produzir intoxicações no homem, com lesões no fígado (Brasil, 2004). Concentrações acima de 2,5 $\mathrm{mg} \mathrm{L}^{-1}$ transmitem sabor amargo à água; acima de $1 \mathrm{mg} \mathrm{L}^{-1}$ produzem coloração em louças e sanitários. Para peixes, muito mais que para o homem, as doses elevadas de cobre são extremamente nocivas. Concentrações de $0,5 \mathrm{mg} \mathrm{L}^{-1}$ são letais para trutas, carpas, bagres, peixes vermelhos de aquários ornamentais e outros. Os micro-organismos morrem em concentrações acima de $1,0 \mathrm{mg} \mathrm{L}^{-1}$ (CETESB, 2010). O padrão de potabilidade para o cobre, de acordo com a Portaria n. 518 de 25 de Março de 2004 do Ministério da Saúde é de $2 \mathrm{mg} \mathrm{L}^{-1}$ (Brasil, 2004).

Ferro total: Observa-se que somente no período seco os valores de ferro total apresentaram, nos pontos B e D, variabilidade em relação aos demais pontos no mesmo período. No período chuvoso não houve diferença significativa (Tabela 3). Nas águas superficiais o nível de ferro aumenta nas estações chuvosas devido ao carreamento de solos e à ocorrência de processos de erosão das margens (CETESB, 2010). Verificou-se, então, que no período chuvoso a concentração do córrego ultrapassou o permitido pela legislação, que é de $0,3 \mathrm{mg} \mathrm{L}^{-1}$.

Franco \& Hernandez (2009) encontraram, estudando a qualidade de água na microbacia do Coqueiro, SP, valores de ferro total 1,5 $\mathrm{mg} \mathrm{L}^{-1}$, valores esses superiores ao valor máximo encontrado nos pontos de amostragem localizados no córrego Jurubatuba.

A Resolução n. 357/2005 (Brasil, 2005) e a portaria n. 518/2004 do Ministério da Saúde (Brasil, 2004) estabeleceram, como valor máximo permitido de ferro dissolvido em corpos hídricos classe 2 e padrão de potabilidade na água, a concentração de $0,3 \mathrm{mg} \mathrm{L}^{-1}$. Brasil (2011) estabeleceu, ainda, que o padrão de lançamento de ferro dissolvido nos corpos hídricos seja no máximo $15 \mathrm{mg} \mathrm{L}^{-1}$. Para o ponto $\mathrm{D}$ verificase, em ambos os períodos, que as concentrações ficaram bem abaixo deste limite.
Manganês: No período seco não houve diferença significativa entre os pontos de amostragem e, no período chuvoso, a concentração de $\mathrm{Mn}$ no ponto A foi maior que nos demais pontos amostrados (Tabela 3). O manganês ocorre naturalmente na água superficial e subterrânea; no entanto, as atividades antropogênicas são também responsáveis pela contaminação da água. Raramente atinge concentrações de $1,0 \mathrm{mg} \mathrm{L}^{-1} \mathrm{em}$ águas superficiais naturais e normalmente está presente em quantidades de $0,2 \mathrm{mg} \mathrm{L}^{-1}$ ou menos (CETESB, 2010) sendo os valores obtidos na água do córrego próximos aos citados por este autor.

$\mathrm{O}$ valor médio de manganês nos pontos $\mathrm{B}, \mathrm{C}$ e $\mathrm{D}$, período seco e chuvoso, foi superior ao padrão permitido pela Resolução Conama n. 357/2005, ou seja, de $0,1 \mathrm{mg} \mathrm{L}^{-1}$ para águas doce de classe 2. Além do mais, os valores do efluente (ponto A) períodos seco e chuvoso, também foram superiores aos dos padrões estabelecidos, ou seja, no máximo $1,0 \mathrm{mg} \mathrm{L}^{-1}$ (Brasil, 2011).

Fósforo: Os valores de fósforo encontrados em todos os pontos do período seco diferiram significativamente; apesar disto se constatou, no período chuvoso, diferença estatística do ponto $\mathrm{A}$, em relação aos demais, neste mesmo período, podendo esta diferença ser atribuída ao aumento do número de abate de animais. $O$ fósforo, analogamente ao nitrogênio, é um nutriente muito importante para o crescimento e reprodução de micro-organismos que promovem a estabilização da matéria orgânica, porém o efluente rico em fósforo pode provocar proliferação excessiva de algas no curso d'água receptor (Silva et al., 2003).

A legislação estabelece uma concentração de $0,02 \mathrm{mg} \mathrm{L}^{-1}$ de fósforo em ambiente lêntico mas no caso do córrego Jurubatuba, trata-se de um ambiente lótico. Lucas et al. (2010) encontraram no período seco, estudando os componentes presentes na água em uma microbacia hidrográfica do Rio Piracicaba, SP, concentrações de fosfato variando entre 0,14 e $0,49 \mathrm{mg} \mathrm{L}^{-1}$, maiores que as encontradas no córrego Jurabatuba para o mesmo período; já no período chuvoso este autor obteve valores entre $0,08 \mathrm{e} 0,29 \mathrm{mg} \mathrm{L}^{-1}$, embora menores que os encontradas no córrego durante o período das chuvas. Verificou-se também que as concentrações de fósforo lançadas no córrego provocaram, nas águas do córrego, um aumento considerável deste elemento.

Sódio: Observou-se diferença significativa de sódio presente no efluente em relação aos demais pontos analisados no córrego, nos períodos seco e chuvoso (Tabela 3 ).

O lançamento de efluente no ponto $\mathrm{D}$, nos dois períodos, não contribui para uma mudança significativa nas concentrações de sódio dos demais pontos.

Condutividade elétrica: Os valores encontrados para os períodos seco e chuvoso no córrego, antes do lançamento do efluente tratado, foram 2,31 e 1,96 dS m $\mathrm{d}^{-1}$, respectivamente. Ao estudar os constituintes presentes na água em uma microbacia hidrográfica do Rio Piracicaba, SP, Lucas et al. (2010) encontraram valores entre 237 e $774 \mu \mathrm{S} \mathrm{cm}^{-1}$ no período seco e de 7,5 e $774 \mu \mathrm{S} \mathrm{cm}^{-1}$ no período chuvoso. 
Queiroz et al. (2010) observaram valores de condutividade elétrica entre 12 e $19 \mu \mathrm{S} \mathrm{cm}^{-1}$ na bacia hidrográfica de Sanga Mandarina, em Cascavel, PR. De maneira geral, o efluente elevou a condutividade elétrica nos pontos à jusante do ponto de lançamento no córrego.

\section{Conclusões}

1. As concentrações de sódio, carbono orgânico total (COT) e fósforo, não apresentaram valores que interferissem estatisticamente nas águas do córrego.

2. A concentração de demanda biológica de oxigênio apresentou aumento no período seco mas não apresentou diferença no período chuvoso.

3. As concentrações de amônia, condutividade elétrica, nitrato, nitrito e dureza, aumentaram nos pontos à jusante do lançamento do efluente no córrego.

4. Os valores de $\mathrm{pH}$, amônia, nitrato e cloreto nos períodos seco e chuvoso, atendem aos padrões da Resolução Conama n. 357 para água de classe 2 , não interferindo na qualidade da água do córrego Jurubatuba.

5. A turbidez, alumínio, manganês e demanda biológica de oxigênio no efluente tratado nos períodos seco e chuvoso, foram maiores ao permitido para lançamento em corpos hídricos de classe 2 .

6. As concentrações de ferro total no efluente se alternaram entre moderado e elevado risco de entupimento de emissores quando utilizados na irrigação, tanto no período seco como no chuvoso.

\section{Agradecimentos}

Ao CNPq, pela concessão de auxílio financeiro e bolsa de estudo em prol da realização desta pesquisa (Processo: 552363/2007-3).

\section{Literatura Citada}

Aguilar, M. I.; Sáez, J.; Lloréns, M.; Soler, A.; Ortuño, J. F. Nutrient removal and sludge production in the coagulationflocculation process. Water Research, v.36, p.2910-2919. 2002.

APHA - American Public Health Association. Standard methods

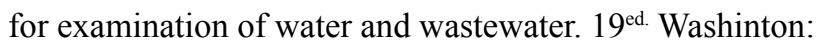
American Public Health Association, 1995. 1193p.

Arraes, F. D. D. Identificação dos íons determinantes da condutividade elétrica nas águas do Rio Trussu. Revista Ciência Agronômica, v.40, p.346-355, 2009.

Bernardo, S.; Soares, A. A.; Mantovani, E. C. Manual de irrigação. 8.ed. Viçosa: UFV, 2006. 625p.

Bonnet, B. R. P.; Ferreira, L. G.; Lobo, F. C. Relações entre qualidade da água e uso do solo em Goiás: Uma análise à escala da bacia hidrográfica. Revista Árvore, v.32, p.311-322. 2008.

Brasil. Portaria MS. Ministério da Saúde ${ }^{\circ} 518$ de 25 de Março de 2004. http://www.agrolab.com.br/portaria\%20518_04. pdf. 19 Jun. 2010.

Brasil. Resolução CONAMA. Conselho Nacional do Meio Ambiente $\mathrm{n}^{\circ} .357$ de 17 de março de 2005. Diário Oficial da República Federativa do Brasil, Brasília, DF, 2005. 23p.
Brasil. Resolução CONAMA. Conselho Nacional do Meio Ambiente $\mathrm{n}^{\circ} 430$ de 13 maio de 2011. Diário Oficial da República Federativa do Brasil, Brasília, DF, n.92 de 16/05/2011 p.89.

Carvalho, C. F.; Ferreira, A. L.; Stapelfeldt, F. Qualidade das águas do ribeirão Ubá - MG. Revista Escola Minas, v.57, p. 165-172, 2004.

Castro, J. D. B. Anápolis, progresso e desenvolvimento, um estudo econômico. Revista de Economia da UEG, v.5, p.22-39, 2009.

CETESB - Companhia de Tecnologia de Saneamento Ambiental. .Variáveis de qualidade das águas. $<$ http://www. cetesb.sp.gov.br/Agua/rios/variaveis.asp>. 17 Jun. 2010.

Donadio, N. M. M.; Galbiatti, J. A.; Paula, R. C. Qualidade da água de nascentes com diferentes usos do solo na Bacia Hidrográfica do Córrego Rico, São Paulo, Brasil. Engenharia Agrícola, v.25, p.115-125, 2005.

Franco, R. A. M.; Hernandez, F. B. T. Qualidade da água para irrigação na microbacia do Coqueiro, Estado de São Paulo. Revista Brasileira de Engenharia Agrícola Ambiental v.13, p.772-780, 2009.

Igbinosa, E .O.; Okoh. A. I. Impact of discharge wastewater effluents on the physico-chemical qualities of a receiving watershed in a typical rural community. International Journal Environmental Science e Technology, v.6, p.175$182,2009$.

José, J. V.; Ribas, M. M. F.; Freitas, P. S. L.; Francisconi Júnior, J. P. Efeito da aplicação de efluente de abatedouro bovino tratado em lagoas de estabilização no solo e no desenvolvimento do milho. Pesquisa Aplicada e Agrotecnologia, v.2, p.51-59, 2009.

Lucas, A. A. T.; Folegatti, M. V.; Duarte, S. Qualidade da água em uma microbacia hidrográfica Rio Piracicaba, SP. Revista Brasileira de Engenharia Agrícola Ambiental, v.14, p.937-943, 2010.

Machado, P. J. O.; Valle, G. M.; Rinco, L.; Carmo, L. F. Z.; Latuf, M. O. Qualidade das águas do Rio Paraibuna no trecho urbano de Juiz de Fora/MG. Revista Virtú, v.1, p.43-57, 2005.

Mansor, M. T. C.; Teixeira Filho, J.; Roston, D. M. Avaliação preliminar das cargas difusas de origem rural, em uma subbacia do rio Jaguari, SP. Revista Brasileira de Engenharia Agrícola e Ambiental, v.10, p.715-723, 2006.

Mees, J. B. R.; Gomes, S. D.; Vilas Boas, M. A.; Fazolo, A.; Sampaio, S. C. Removal of organic matter and nutrients from slaughterhouse wastewater by using Eichhornia crassipes and evaluation of the generated biomass composting. Engenharia Agrícola, v.29, p.466-473, 2009.

Pacheco, J. A. S.; Wolff, D. B. Tratamento dos efluentes de um frigorífico por sistema australiano de lagoas de estabilização. Disc. Scientia. Série: Ciências Naturais e Tecnológicas, v.5, p.67-85, 2004.

Palácio, H. A. Q; Andrade, E. M; Lopes, F. B; Barros, D. M; Arraes, A. F. D. D. Similaridade da qualidade das águas superficiais da Bacia do Curu, Ceará. Ciência Rural v.39, p.2494-2500. 2009. 
Queiroz, M. M. F. Iost, C.; Gomes, S. D. Influência do uso do solo na qualidade da água de uma microbacia hidrográfica rural. Revista Verde de Agroecologia e Desenvolvimento Sustentável, v.5, p.200-210, 2010.

Rabelo, C. G.; Ferreira, M. E; Araújo, J. V. G . Influência do uso do solo na qualidade da água no bioma Cerrado: um estudo comparativo entre bacias hidrográficas no Estado de Goiás Brasil. Revista Ambiente e Água, v.4, p.172-187, 2009.

Santos, L. R.; Lopes, L. M. Bacia do Córrego da Lagoinha em Anápolis (GO): Morfopedologia, uso da terra e problemas decorrentes. In: Simpósio Brasileiro de Geografia, 13, 2007, Viçosa. Anais...Viçosa: UFV, 2007. CD-Rom

Silva, F. F.; Freitas, P. S. L.; Bertonha, A.; Rezende, R.; Gonçalves, A. C. A.; Dallacort, R. Flutuações das características químicas do efluente industrial de fecularia de mandioca. Acta Scientiarum, v.25, p.167-75, 2003.
SIMEGO - Sistema de meteorologia e hidrologia do estado de Goiás. http://www.simego.sectec.go.gov.br/. 2 Jan. 2010.

Sperling, M. von. Princípio do tratamento biológico de águas residuárias. 3.ed. Belo Horizonte: UFMG, 2005. 452p.

Thebaldi, M. S; Sandri, D.; Felisberto, A. B.; Rocha. M. R. da.; Araújo Neto, S. de. Qualidade da água de um córrego sob influência de efluente tratado de abate bovino. Revista Brasileira de Engenharia Agrícola e Ambiental, v.15, p.302309, 2010.

Vivan, M.; Kunz, A.; Stlberg, J.; Perdomo, C.; Techio, V. H. Eficiência da interação biodigestor e lagoas de estabilização na remoção de poluentes em dejetos de suínos. Revista Brasileira de Engenharia Agrícola e Ambiental, v.14, p.320325. 2010. 